\title{
INTRODUÇÃO À EDIÇÃO ESPECIAL DAS MELHORES PRODUÇÕES CIENTÍFICAS SELECIONADAS DO ENEO 2014 SOBRE ESTUDOS ORGANIZACIONAIS BRASILEIROS
}

Os artigos mais bem avaliados no VIII Encontro da Divisão de Estudos Organizacionais (EnEO) da Associação Nacional de Pós-Graduação e Pesquisa em Administração (Anpad), ocorrido em 20I4 na cidade de Gramado/RS, gozaram de uma nova possibilidade de reconhecimento que se consubstancia neste número especial da Revista de Administração Mackenzie (RAM). Assim sendo, os dez melhores artigos ranqueados pelo sistema de avaliação do VIII EnEO e os dois melhores artigos de cada linha temática do encontro, indicados pelos respectivos líderes de tema, foram submetidos à RAM para concorrer à publicação.

O primeiro critério de seleção consistiu no índice de saturação de artigos já publicados no ano de 20I4, considerando região geográfica, estado, instituição de ensino superior e autor. Os artigos que não se enquadraram nesses critérios não puderam ser encaminhados para avaliação para esta edição especial da RAM e foram redirecionados para concorrer às edições regulares. Os demais artigos foram avaliados pelos pareceristas da RAM, e, no final do processo, selecionaram-se oito artigos para compor este número especial da revista.

Os artigos selecionados refletem a diversidade dos estudos organizacionais brasileiros em termos metodológicos, epistemológicos e geográficos. Constata-se, nos artigos selecionados para este número, a presença de trabalhos teórico-empíricos que utilizam metodologias qualitativas e quantitativas, bem como de natureza teórico-metodológica. Dos diversos paradigmas que permeiam a área, encontram-se representados neste número artigos que se afiliam tanto a paradigmas funcionalistas quanto aos estudos críticos e culturais, o que também influencia e reflete a heterogeneidade epistemológica da área com a presença de abordagens gerencialistas, marxistas, sociológicas, pós-marxistas/pós-estruturalistas e estruturais construtivistas, englobando inclusive trabalhos cujo lócus de análise é a administração pública e privada. Em termos geográficos, destacam-se 
três regiões brasileiras (Nordeste, Sul e Sudeste), nas quais a produção intelectual da área de estudos organizacionais encontra-se consolidada ou em vias de consolidação. Contudo, isso também aponta a necessidade de desenvolvimento da área nas universidades das regiões Norte e Centro-Oeste do Brasil.

Portanto, após esta contextualização metodológica, geográfica e epistemológica dos artigos, o que também nos dá alguns indicativos acerca da produção da área de estudos organizacionais no Brasil, as principais características dos artigos selecionados e publicados neste número são apresentadas.

$\mathrm{O}$ artigo "Institutional work e conhecimento em redes interorganizacionais: uma proposta para investigar APLs” é uma proposição teórica/metodológica para o estudo de arranjos produtivos locais (APLs) fundamentado em uma abordagem institucional. Para tanto, são desenvolvidas I3 hipóteses que permitem uma análise mais acurada do microprocesso de institucionalização dos APLs, levando em consideração aspectos do ambiente institucional, do ambiente técnico e do contexto relacional no desenvolvimento dessas hipóteses.

Buscando também entender a institucionalização da pesquisa sobre gênero nas escolas de administração do país, o artigo "A produção científica em gênero no Brasil: um panorama dos grupos de pesquisa de administração" mapeia as pesquisas e publicações sobre gênero na área de administração. Utilizando-se de estatística descritiva em suas análises, o artigo demonstra que, dos 32 grupos de pesquisa identificados como desenvolvedores de trabalhos sobre o tema, a maioria deles ainda possui publicações esporádicas sobre o gênero, e boa parte dessas publicações encontra-se centrada e focada em apenas três grupos de pesquisa localizados nas regiões Sul e Sudeste. As relações entre os líderes dos 32 grupos de pesquisa não são estabelecidas a ponto de promover redes de pesquisas e publicações em conjunto na área.

Contrapondo-se às políticas gerencialistas direcionadas ao trabalho artesanal desenvolvidas pelo Serviço Brasileiro de Apoio às Micro e Pequenas Empresas (Sebrae), o artigo "De artesão a empreendedor: a ressignificação do trabalho artesanal como estratégia para a reprodução de relações desiguais de poder" debate os efeitos dessas políticas no processo de ressignificação do trabalho artesanal e na construção identitária do próprio artesão. A comoditização e a imposição da lógica capitalística/gerencialista sobre o trabalho artesanal são problematizadas, focando principalmente no discurso oficial do Sebrae que promete ao artesão inclusão social por meio da adoção dessa lógica, mas que acaba reproduzindo novas modalidades de desigualdades sociais e de acesso ao poder.

O artigo "Alberto Guerreiro Ramos: contribuições da redução sociológica para o campo científico da administração pública no Brasil” traz contribuições teóricas e conceituais, objetivando delimitar o campo de estudo da administração 
pública no Brasil. Fundamentado no reducionismo sociológico proposto por Guerreiro Ramos e no construtivismo estrutural de Bourdieu, o artigo busca discutir e fomentar a construção de uma identidade para o campo científico da administração pública, bem como promover uma maior proximidade entre as pesquisas acadêmicas desenvolvidas pelo campo e a real satisfação das necessidades da sociedade brasileira, pois, somente a partir dessa aproximação, pode-se reconciliar a eficiência organizacional com formas democráticas de gestão.

Ao compreender a produção de sentidos atribuídos a cidades pelos mitos fundadores e pelas tradições inventadas, o artigo "Mitos fundadores, tradições inventadas e sentidos de cidade: uma incursão pela velha e nova Cataguases-MG" nos conduz a uma análise histórica dos aparatos legais, políticos, culturais e econômicos na construção de significados. Baseado em uma abordagem marxista do discurso, o artigo demonstra a relação dialética entre a superestrutura e a vida social na cidade de Cataguases. As lutas locais entre as elites que representam os setores econômicos agrários e industriais marcam a construção de sentidos sobre a cidade e produzem um ideário e uma separação entre o que é moderno e conservador, influenciando inclusive a arquitetura da cidade.

A importância do Carnaval como elemento aglutinador de diversos grupos sociais é retratada no artigo "A teoria do discurso do Carnaval Multicultural do Recife: uma análise da festa carnavalesca de Recife à luz da teoria de Laclau e Mouffe". A existência de um ponto nodal possibilita que o Carnaval de Recife una heterogêneos e antagônicos agentes na produção de significados sobre a festa. Fundamentado na abordagem pós-marxista/pós-estruturalista de Laclau e Mouffe, o artigo busca entender o processo de construção discursiva em torno do Carnaval de Recife por meio de políticas públicas.

Com foco no trânsito entre indivíduos e organizações, abordando a percepção de professores sobre práticas organizacionais em instituições educacionais, o artigo "Justiça organizacional percebida por professores dos ensinos básico, técnico e tecnológico", além de adaptar uma escala de mensuração para o contexto brasileiro, revela que professores efetivos e substitutos avaliam de forma diferente a justiça organizacional percebida.

Por sua vez, o artigo "Psychological well-being and psychological distress for professors in Brazil and Canada" revela que não foi encontrada diferença significativa entre as amostras dos professores que atuam em universidades públicas brasileiras e canadenses quanto às dimensões de saúde mental, já que os brasileiros ainda percebem um maior equilíbrio entre vida profissional e privada.

Por fim, gostaríamos de agradecer ao corpo editorial da Revista de Administração Mackenzie (RAM) que aceitou e acolheu a proposta de publicar este número especial de artigos mais bem avaliados no EnEO 2014. 
A consubstanciação deste número é fruto de trabalho conjunto e do compromisso de todas as partes envolvidas com o fortalecimento da área de estudos organizacionais no Brasil.

Boa leitura para todos!

ANA SILVIA ROCHA IPIRANGA Doutora em Psicologia do Trabalho e da Organização pela Università degli Studi di Bologna (Itália). Professora adjunta do Programa de Pós-Graduação em Administração da Universidade Estadual do Ceará (Uece). Avenida Abolição 2.480/1.004, Meireles, Fortaleza - CE - Brasil - CEP 60165-080 E-mail:ana.silvia@pq.cnpq.br

ELOISIO MOULIN DE SOUZA Doutor em Psicologia pelo Programa de Pós-Graduação em Psicologia da Universidade Federal do Espírito Santo (Ufes). Professor adjunto do Departamento de Administração da Universidade Federal do Espírito Santo (Ufes). Avenida Fernando Ferrari, 514, Goiabeiras, Vitória - ES - Brasil - CEP 29075-910 E-mail: eloisiomoulin@gmail.com

\section{MARIA LUISA MENDES TEIXEIRA}

Doutora em Administração de Empresas pela Faculdade de Economia, Administração e Contabilidade da Universidade de São Paulo (USP). Professora adjunta do Programa de Pós-Graduação em Administração de Empresas da Universidade Presbiteriana Mackenzie (PPGA-UPM). Rua da Consolação, 930, Consolação, São Paulo - SP - Brasil - CEP 01302-907 E-mail: malluluisa@gmail.com 